\title{
Meal replacement soups and shakes: do they have a place in public health practice to manage weight loss?
}

\section{Bronwyn McGilla,b,c,e, Anne C Grunseita,b,c, Philayrath Phongsavanª, Claudia Harperb,d and Blythe J O'Hara ${ }^{a, b}$}

a Prevention Research Collaboration, Sydney School of Public Health, University of Sydney, NSW, Australia

${ }^{b}$ Charles Perkins Centre, University of Sydney, NSW, Australia

c The Australian Prevention Partnership Centre, Sydney, NSW, Australia

${ }^{d}$ The Boden Institute of Obesity, Nutrition, Exercise and Eating Disorders, University of Sydney, NSW, Australia

e Corresponding author: bronwyn.mcgill@sydney.edu.au

\section{Article history}

Publication date: March 2021

Citation: McGill B, Grunseit AC,

Phongsavan P, Harper C, O'Hara BJ. Meal replacement soups and shakes: do they have a place in public health practice to manage weight loss? Public Health Res Pract. 2021;31(1):e30012002. First published: 29 January 2020. https://doi. org/10.17061/phrp30012002

\section{Background}

Nine per cent of Australian adults report dieting to lose weight, and $49 \%$ of these describe their diets as 'low calorie'. 'An online search for 'low calorie/ energy diet products' reveals many advertisements for commercially available low- and very low-energy meal-replacement (MR) products, including promotions for 'soups and shakes'. Evidence supports low- and very lowenergy MRs as a successful strategy for weight loss in overweight and obese individuals. , $3^{3}$ Australian clinical practice guidelines for overweight and obesity management include changing lifestyle behaviours and the use of very lowenergy diets as effective in supporting weight loss for overweight and obese adults. ${ }^{4}$ Considering the evidence supporting their use to reduce energy intake, MRs may be underutilised in weight loss management. ${ }^{5}$ Further, the role of their use in public health is unclear. Although many studies have investigated the efficacy of MRs, few have explored participant perceptions of using these options for weight-loss management. In those studies that have explored this, MRs were positively perceived, and considered convenient and easy to use. 6,7

The Healthy Weight for Life (HWFL) program is an 18-week weight-loss lifestyle-modification program for overweight or obese adults with chronic disease who have private health insurance. ${ }^{8}$ The program includes physical activity and dietary recommendations, incorporating a portion-controlled eating plan including MRs under the brand name KicStart, in the form of a shake or soup. Past participants of the program have lost on average, approximately $7-8 \%$ of their baseline weight.., 10 We undertook qualitative research to investigate an additional maintenance phase for HWFL participants. Six focus groups were conducted during November 2016, with 28 English-speaking participants who had completed HWFL within the past year (53.6\% of participants were male, $46.4 \%$ female, $85.7 \%$ aged 55 years and older, $82.1 \%$ from most advantaged areas, $96.4 \%$ from major cities; $60.7 \%$ of whom had maintained their weight loss or lost further weight after 
completing the program). The focus groups explored incentives for weight-loss maintenance using a thematic inductive approach. ${ }^{11}$ Participants spoke spontaneously and at length about their experiences of using MRs for weight loss management. Although not the primary research focus, participants' enthusiasm for discussing soups and shakes was notable. This study aims to provide initial insights into participant experiences of using MRs in the hope of stimulating debate within public health about the place they may (or may not) have in promoting healthy weight-loss management across the population.

\section{Meal replacements: participant perceptions}

Overall, MR options of soups and shakes were favourably perceived and seen as a major feature of HWFL (Table 1). Participants noted that they were convenient and fitted into their lives without much effort. They generally viewed MRs as an effective weight-loss strategy, and integral to ongoing weight-loss management. A stronger emphasis was placed on soups and shakes than on physical activity and healthy diet components of the program, suggesting that MRs were more highly valued than other program components.

Many participants attributed weight loss to MRs, in turn providing motivation for further weight-loss management. Although some expressed boredom with available flavours, many continued using MRs, primarily to replace one meal per day (either breakfast or lunch), following the 18-week program, to regulate their weight. Our research advances previous findings that reported only intention to use MR diets intermittently ${ }^{7}$, with our observations showing that participants proactively use partial meal replacement for ongoing weight-loss management. The value participants place on soups and shakes raises the question: why don't more participants place similar value on a balanced diet and sufficient physical activity? Possibly, MRs provide a tangible, seemingly quick and easy way of addressing weight loss, as opposed to the complex behavioural challenges of dietary or physical activity change.

\section{Implications and future directions}

There is currently no consensus or guidance on how MRs should be used for weight-loss management. Our observations, while preliminary, suggest there may be a role for partial meal replacement, particularly given the acceptability of this option to consumers for weight-loss management. Other than for those with existing dietary intolerances, adverse effects of MRs (for partial meal replacement) are reported to be mild in nature. ${ }^{2}$ Our participants first experienced using MRs in a supported and supervised setting. However, the extent and range of use of commercially available MRs in the general population with overweight and obesity is unknown. The accessibility, acceptability and the degree to which users believe MRs support successful weight loss should compel provision of an evidence-based viewpoint on the role of MRs for real-world weight management.

Currently, public health messages for weight management and improving obesity-related health outcomes mostly advocate lifestyle change. Public health practitioners are well placed to engage in future study and debate about whether MRs could or should be promoted as part of an evidence-based weight-loss management strategy, in the short and/or long term. Future research should also focus on the equitable use of MRs in weight management in terms of perceived and actual effectiveness, value for money and product satisfaction for individuals from socio-economically

Table 1. Example participant quotes about using meal replacement soups and shakes in weight-loss maintenance

\begin{tabular}{|c|c|c|}
\hline Theme & Reinforcing & Contrasting \\
\hline Flavour preferences & $\begin{array}{l}\text { "... it's pretty tasty. Yeah, it's a good } \\
\text { product. It's nothing bland." } \\
\text { Male, } 69 \text { years }\end{array}$ & $\begin{array}{l}\text { "You've only got } 2 \text { or } 3 \text { choices [that they enjoyed]. You soon } \\
\text { get sick of it." } \\
\text { Male, } 66 \text { years }\end{array}$ \\
\hline Motivation & $\begin{array}{l}\text { "I started to want to eat healthier because } \\
\text { I was losing weight. It gave me enthusiasm } \\
\text {... I don't want to put it back on again ..." } \\
\text { Female, } 57 \text { years }\end{array}$ & $\begin{array}{l}\text { "You get tired of just drinking, get bored with drinking the } \\
\text { shakes all the time." } \\
\text { Female, } 56 \text { years }\end{array}$ \\
\hline $\begin{array}{l}\text { Routine and } \\
\text { convenience }\end{array}$ & $\begin{array}{l}\text { "I found the sachets really useful ... it was } \\
\text { really quick. I realised it was just a short- } \\
\text { term thing, a kick-start thing." } \\
\text { Female, } 59 \text { years }\end{array}$ & $\begin{array}{l}\text { "It's got all the right vitamins and minerals and all those } \\
\text { things you need, but I found it hard." } \\
\text { Female, } 55 \text { years }\end{array}$ \\
\hline Long-term use & $\begin{array}{l}\text { "I'm still doing this } 8 \text { months later. Now, the } \\
\text { days I have breakfast cereal, I have a shake } \\
\text { for lunch." } \\
\text { Male, } 78 \text { years }\end{array}$ & $\begin{array}{l}\text { "I focused more on the zero foods and more of the natural, } \\
\text { changing my habits and supermarket shopping." } \\
\text { Male, } 47 \text { years }\end{array}$ \\
\hline
\end{tabular}


disadvantaged areas or culturally and linguistically diverse backgrounds. The question of how best to incorporate the use of MRs into weight-loss management - if at all - represents an unexplored opportunity for public health practitioners.

\section{Acknowledgements}

This study was supported by funding from The Australian Prevention Partnership Centre. BM is supported by a University Postgraduate Award at the University of Sydney.

\section{Peer review and provenance}

Externally peer reviewed, not commissioned.

\section{Competing interests}

None declared.

\section{Author contributions}

$\mathrm{BM}, \mathrm{AG}, \mathrm{PP}$ and $\mathrm{BOH}$ contributed to the design of the evaluation. $\mathrm{BM}$ and $\mathrm{BOH}$ coded the data and $\mathrm{BM}, \mathrm{BOH}$ and $A G$ were involved in the data analysis. BM prepared the first draft of the manuscript and BM, AG, PP, CH and $\mathrm{BOH}$ contributed to subsequent drafts. All authors read and approved the final version of the manuscript.

\section{References}

1. Australian Bureau of Statistics. Australian Health Survey: nutrition first results - food and nutrients, 2011-12. Canberra: ABS; 2014 [cited 2019 Dec 16]. Available from: www.abs.gov.au/ausstats/abs@.nsf/Lookup/4364.0. 55.007main+features12011-12

2. Parretti $H$, Jebb $S$, Johns $D$, Lewis $A$, Christian-Brown A, Aveyard P. Clinical effectiveness of very-low-energy diets in the management of weight loss: a systematic review and meta-analysis of randomized controlled trials. Obes Rev. 2016;17(3):225-34.
3. Hamdy $\mathrm{O}$, Zwiefelhofer D. Weight management using a meal replacement strategy in type 2 diabetes. Curr Diab Rep. 2010;10(2):159-64.

4. National Health and Medical Research Council. Clinical practice guidelines for the management of overweight and obesity in adults, adolescents and children in Australia. Melbourne: NHMRC; 2013 [cited 2019 Dec 16]. Available from: www.nhmrc.gov.au/about-us/publications/ clinical-practice-guidelines-management-overweightand-obesity

5. Collins C. Survey of dietetic management of overweight and obesity and comparison with best practice criteria. Nutr Diet. 2003;60(3):177-84.

6. Rehackova L, Araújo-Soares V, Adamson A, Steven S, Taylor R, Sniehotta F. Acceptability of a very-low-energy diet in Type 2 diabetes: patient experiences and behaviour regulation. Diabet Med. 2017;34(110):1554-67.

7. Herriot A, Thomas D, Hart K, Warren J, Truby H. A qualitative investigation of individuals' experiences and expectations before and after completing a trial of commercial weight loss programmes. J Hum Nutr Diet. 2008;21(1):72-80.

8. Prima Health Solutions. Healthy Weight for Life. Sydney: Prima Health Solutions [cited 2019 Dec 11]. Available from: healthyweightforlife.com.au

9. Atukorala I, Makovey J, Lawler L, Messier SP, Bennell K, Hunter DJ. Is there a dose response relationship between weight loss and symptom improvement in persons with knee osteoarthritis? Arthritis Care Res. 2016;68(8):110614.

10. Makovey J, Lawler L, Bennell KL, Hunter DJ. Dose response relationship between weight loss and improvement in quality of life in persons with symptomatic knee osteoarthritis. Osteoarthritis Cartilage. 2015;23:A386.

11. McGill B, O'Hara B, Grunseit AC, Bauman A, Osborne D, Lawler $L$, et al. Acceptability of financial incentives for maintenance of weight loss in mid-older adults: a mixed methods study. BMC Public Health. 2018;18(1):244.

\section{Copyright: (C) $(1)(0$}

(C) 2020 McGill et al. This article is licensed under the Creative Commons Attribution-NonCommercial-ShareAlike 4.0 International Licence, which allows others to redistribute, adapt and share this work non-commercially provided they attribute the work and any adapted version of it is distributed under the same Creative Commons licence terms. See: www.creativecommons.org/licenses/by-nc-sa/4.0/ 